\title{
Participação popular e gestão democrática - Salvador como metáfora
}

\author{
Popular participation and democratic management - \\ Salvador as a metaphor
}

Inaiá Maria Moreira Carvalho [I]

Maria Elisabete Pereira dos Santos [II]

\section{Resumo}

Este artigo discute como se processa a participação popular na elaboração dos planos diretores nas cidades brasileiras, definidos como instrumentos de democratização da gestão da res publica, abordando o caso de Salvador. Trata-se de refletir sobre os limites e as possibilidades do exercício da democracia no atual contexto de peemedebização da política. Fundamentam essa reflexão conceitos como o de participação, direito à cidade e democracia, e as fontes de pesquisa utilizadas foram documentos oficiais e entrevistas semidirigidas. 0 trabalho conclui com a tese de que o recente avanço no processo de democratização da construção do Plano Diretor de Desenvolvimento Urbano encontra limites na persistente situação de desigualdade, na radicalização da instrumentalização da participação, na captura do poder público por interesses privados e no esquecimento da política.

Palavras-chave: participação; democracia; plano diretor; res publica; Salvador.

\begin{abstract}
This paper discusses the role played by popular participation in the preparation of master plans in Brazilian cities, addressing the case of Salvador. Master plans are defined as instruments that democratize the management of the res publica. The paper proposes a reflection on the limits and possibilities of the exercise of democracy in the current context in which the political party known as PMDB has a huge influence in the Brazilian politics. That reflection is supported by concepts such as participation, the right to the city and democracy, and the research sources used in our study were official documents and semi-guided interviews. The study concludes with the thesis that the recent advance in the democratization process of the construction of Salvador's Master Plan finds limits in the persistent situation of inequality, in the radicalization of the instrumentalization of participation, in the government's capture by private interests, and in the abandonment of politics.
\end{abstract}

Keywords: participation; democracy; master plan; res publica; Salvador. 


\section{Introdução}

Este artigo discute como vem se dando a participação popular nos processos de elaboração dos Planos Diretores de Desenvolvimento Urbano (PDDU) nas cidades brasileiras, definidos pelo Estatuto da Cidade como um dos instrumentos básicos para o alcance de uma gestão democrática e do direito à cidade pelo conjunto da população, abordando, mais especificamente, essa participação no caso de Salvador. Analisando a trajetória dos seus últimos planos diretores, constata-se que a capital baiana é um exemplo de como incorporar e esvaziar o instituto da participação em contextos conservadores e autoritários, um padrão de gestão e desenvolvimento urbano que vem tendendo a se atualizar e se ampliar nas cidades e metrópoles do País.

Discute-se a tese de que esse instituto e o recente avanço no processo de democratização da gestão da res publica no Brasil encontraram limites na reduzida permeabilidade do poder público à participação, na captura do poder público por interesses privados e nas históricas desigualdades sociais e urbanas, especialmente acentuadas em algumas regiões e em grandes cidades, como Salvador. As conquistas registradas na democratização de gestões municipais ao longo das décadas passadas, a exemplo de Porto Alegre, Belo Horizonte ou Recife, não se reproduzem e se desdobram em casos como o da capital baiana, na qual a participação vem sendo encarada apenas como o cumprimento de uma obrigação legal e um mecanismo de legitimação. Nesse sentido, Salvador é um exemplo de como incorporar a participação em contextos autoritários e conservadores, convertendo-se em metáfora do esvaziamento político desse processo, que se aprofunda nesse momento de crise e de retorno de projetos políticos conservadores e de cunho privatizante, de forças políticas que, na última década, estiveram mais afastadas do controle da máquina pública.

Fundamentam este trabalho os conceitos de participação e direito à cidade, e as principais referências teóricas utilizadas são Henri Lefebvre, David Harvey, Ermínia Maricato e Leonardo Avritzer, dentre outros. A metodologia de trabalho consiste em consultas bibliográficas, análise de documentos (como as atas das audiências públicas realizadas pela Prefeitura e pela Câmara de Vereadores) e entrevistas com representantes de entidades e movimentos sociais que participaram da discussão do PDDU. 0 texto está estruturado da seguinte forma: a seção dois discute as aporias em torno do plano diretor, da participação e do direito à cidade no Brasil, refletindo sobre os limites e as possibilidades do exercício da democracia brasileira. A seção três trata da experiência de participação no processo de elaboração do plano diretor nas duas últimas décadas, à luz da experiência de Salvador. E, finalmente, a seção quatro apresenta observações finais sobre as aporias da participação no Brasil de hoje.

\section{Plano diretor, participação popular e direito à cidade}

O caráter excludente do desenvolvimento brasileiro manifesta-se especialmente nas grandes cidades e metrópoles do País, nas quais se concentram, tanto a população, o poder, a produção, a riqueza e os elevados padrões de 
consumo, como a vulnerabilidade social e a pobreza, a carência de infraestrutura e de serviços básicos, a precariedade habitacional, as desigualdades, a violência e a degradação ambiental. Contudo, o Brasil dispõe de uma legislação das mais avançadas no que se refere ao enfrentamento dos problemas urbanos, uma vez que, na fase de redemocratização do País, o Movimento Nacional de Reforma Urbana conseguiu inserir na Constituição de 1988 um capítulo dedicado ao desenvolvimento urbano e à função social da cidade. Com o prosseguimento das suas mobilizações, foi aprovado o Estatuto da Cidade (lei n. 10.257, de 7 de junho de 2001), que deu suporte jurídico consistente à ação dos governos e da sociedade organizada para controlar os processos de ocupação e de uso do solo e o desenvolvimento urbano, orientando-os para a democratização do acesso à terra urbana e para a redução das desigualdades, da segregação e da degradação ambiental (Maricato, 2010; Fernandes, 2010).

Incorporando princípios, diretrizes e instrumentos inovadores e direcionados para a promoção do direito à cidade e para sua gestão democrática (como a tributação progressiva, o parcelamento e a edificação compulsórios, a transferência onerosa do direito de construir, a definição de Zonas Especiais de Interesse Social - Zeis e a participação popular na definição das políticas urbanas), o Estatuto estabeleceu as bases para um novo paradigma jurídico-político para o desenvolvimento urbano, valorizando o poder local, os planos diretores de desenvolvimento urbano e a participação da sociedade civil na sua elaboração.

Tendo um caráter plurianual, de acordo com o Estatuto, o plano deve englobar o município como um todo e definir prioridades e diretrizes orçamentárias, com a lei que o institui sendo revista pelo menos a cada dez anos. E para que o caráter autoritário e comumente excludente dos planos e políticas urbanas no País viesse a ser superado, com a sua aproximação da realidade local e uma nova ênfase na qualidade de vida e na inclusão social, é exigido que o executivo e o legislativo municipal garantam a participação da população e das associações representativas dos vários segmentos da comunidade, tanto na definição do conteúdo desse instrumento como na fiscalização da sua implementação. Com a realização de debates, audiências, consultas públicas e conferências e a incorporação de propostas e projetos de iniciativa popular, associados à criação de órgãos colegiados de política urbana, esperava-se viabilizar um novo padrão de intervenção governamental e uma gestão democrática, voltada para a promoção da justiça social e do direito de todos à cidade (Lefebvre, 2001; Harvey, 2014; Fernandes, 2010). Mas, embora não se deva minimizar a importância ou certas conquistas do Movimento de Reforma Urbana e do Estatuto da Cidade, não se pode dizer que essas expectativas tenham se efetivado.

Alguns autores têm assinalado que em certos casos a elaboração e a revisão dos planos diretores têm propiciado a constituição de espaços e o desenvolvimento de debates que levaram a maior apropriação pública das disposições do Estatuto, a maior conhecimento dos problemas e potencialidades dos municípios, das estratégias para o seu desenvolvimento e dos processos de planejamento. Mas há um amplo reconhecimento de que estes pouco contribuíram para a efetivação dos princípios, diretrizes e instrumentos institucionalizados pela nova legislação e para o alcance dos seus objetivos. De maneira geral, eles não 
apresentam um projeto de cidade articulado com as disposições do Estatuto e resultante de negociações e de um pacto social entre os diversos atores e interesses envolvidos com o desenvolvimento urbano. A grande maioria deles tem um caráter bastante genérico, podendo ser qualificada como um discurso politicamente correto, pleno de boas intenções, mas com muito pouca efetividade; entre outros aspectos, porque, em geral, não define prioridades, não está vinculada ao orçamento municipal nem estabelece estratégias e procedimentos mais concretos e pertinentes para assegurar a sua materialização, deixando os gestores "livres" para conduzir o seu mandato a partir de interesses pessoais ou de grupos políticos e econômicos. Além disso, a maioria dos conselhos da cidade ou de desenvolvimento urbano não se encontra instalada, tem um caráter consultivo ou permanece à espera de uma regulamentação, e os mecanismos de participação têm se mostrado problemáticos, com efeitos pelo menos duvidosos.

Em um balanço crítico sobre o conteúdo e as perspectivas desses instrumentos nos anos posteriores ao Estatuto, Santos Junior e Montandon (2011), por exemplo, concluem que, embora tenham contribuído para viabilizar certos avanços, os planos não são frutos de negociações e pactos sociais sobre a gestão pública e sobre questões relevantes, pouco dialogam com o conjunto e com as organizações da sociedade civil e praticamente não têm incorporado as disposições e os novos instrumentos de gestão urbana ou contribuído para a sua efetivação. Conforme os autores, é preciso avançar na discussão sobre a gestão das cidades, "dar efetividade aos canais de participação instituídos e incorporar a população, em especial os segmentos populares historicamente excluídos dos processos decisórios na discussão dos projetos e programas urbanos e no processo de gestão" (ibid., p. 47).

Estudiosos como Vitale (2004), Villaça (2005), Silva (2006), Milani (2007), Avritzer (2007), Nascimento (2008) e Coriolano, Rodrigues e Oliveira (2013) também apresentam considerações e evidências pouco animadoras sobre os impactos dos referidos planos, notadamente no que se refere a condições e efetividade da participação. Discutindo a experiência do município de Palmas, por exemplo, Coriolano, Rodrigues e Oliveira (2013) assinalam que, embora a elaboração do seu plano diretor tenha se dado com o envolvimento da comunidade (por meio de diversas reuniões), os frutos dessa participação foram excluídos quando o projeto chegou à Câmara Municipal, revertendo os resultados anteriores do processo em questão. $E$, em um texto que tem o sugestivo título de "As ilusões do Plano Diretor", Villaça (2005) assume uma postura ainda mais crítica, colocando em questão o significado e a própria relevância desses planos.

Para Villaça, desde o surgimento dos planos diretores no Brasil não se tem notícia de qualquer cidade ou administração municipal que tenha sido pautada por eles, com um nível de abrangência e objetivos que ultrapassem significativamente o zoneamento. A maioria dos artigos desses documentos é constituída por generalidades que não obrigam ninguém a fazer ou a deixar de fazer nada. Esses artigos não levam em conta a diversidade e os conflitos de interesses das diferentes classes sociais no que tange aos problemas urbanos e normalmente ignoram as reivindicações e as urgências das classes populares (como a regularização dos loteamentos clandestinos), além de não apresentarem propostas que 
orientem efetivamente os destinos e o futuro das cidades. Por essas e outras razões, o próprio interesse por eles despertados termina sendo restrito.

Analisando o caso da metrópole paulistana, o autor constatou que, apesar de todo o seu interesse pelas definições relativas à ocupação e ao uso do solo urbano, os representantes do segmento imobiliário não participaram das discussões do plano, uma vez que a defesa desses interesses, normalmente, se efetua em outros espaços e através de outros canais, como a publicação de matérias na imprensa e/ou de negociações e pressões diretas junto ao prefeito e aos vereadores. Os moradores dos bairros populares apresentaram queixas e reivindicações pontuais sobre a presença de buracos e a falta de pavimentação nas ruas, a situação de córregos imundos e cheios de ratos e a frequência de enchentes ou a clandestinidade de seus imóveis, entre outros problemas dessa ordem, mas sem que eles fossem articulados a questões mais gerais do plano, limitando-se a apoiar as propostas de institucionalização das Zeis. Em alguns bairros, as reuniões para a discussão foram breves e/ou terminaram sendo encerradas mais cedo, simplesmente por falta de assunto. Discussões mais acaloradas ocorreram apenas em algumas áreas de média e de alta renda, relacionadas à possibilidade de algumas intervenções da prefeitura, mudanças no zoneamento e gabarito ou a conflitos dos moradores que defendiam o caráter estritamente residencial das áreas com bares, restaurantes e outras casas noturnas também ali concentradas.

Também é ilustrativa a experiência de Curitiba na revisão obrigatória do plano diretor em 2014, quando organizações da sociedade civil se articularam através da Frente Mobiliza
Curitiba, se capacitaram e se mobilizaram para intervir na referida revisão. Nesse processo, tiveram que enfrentar desafios, como a falta de compreensão da necessidade de compartiIhar decisões com a sociedade a partir de novo modelo de democracia participativa instituído pela Constituição de 1988 e de uma cultura de participação entre os gestores públicos, técnicos e a própria população; a carência de metodologias mais adequadas à promoção da escuta, do debates e da participação; o distanciamento entre a linguagem tecnocêntrica e a linguagem leiga; ou a sobrevalorização do conhecimento dos técnicos da gestão pública em relação aos demais segmentos da população.

Com a sua capacitação, mobilização e uma disputa continuada por uma efetiva intervenção no plano, o Mobiliza Curitiba tornou-se uma referência no que tange aos problemas da cidade e ao seu enfrentamento, contribuindo para ampliar a discussão sobre eles, influenciando o diálogo com o poder público e a sua própria postura sobre algumas questões. Desse processo, resultaram certas conquistas e alguns avanços, conforme avaliação apresentada por Coelho (2015). A sociedade civil saiu fortalecida e o poder público e seus técnicos também aprenderam ao longo das discussões. O novo plano incorporou temas e metas até então ausentes, como o combate aos vazios urbanos e a subutilização de imóveis em áreas centrais e com boa infraestrutura, o IPTU progressivo, a diversificação da tipologia das Zeis e a contribuição de uma cota de solidariedade por parte dos grandes investimentos imobiliários para ser aplicada na provisão de habitação de interesse social.

Contudo, o texto do plano manteve um caráter genérico, esvaziado de força diretiva e de efetividade, pois a aplicação desses 
dispositivos depende da aprovação de 16 leis específicas, e não foram definidos sequer os prazos para a sua elaboração; observando-se, também, uma regulamentação seletiva dos instrumentos de política urbana. Aqueles instrumentos de interesse e com um declarado apoio do mercado imobiliário, como o do solo criado, das concessões urbanísticas e das operações consorciadas urbanas, foram mantidos e reforçados, enquanto medidas associadas à regularização fundiária, à provisão de habitações de interesse social ou ao combate à especulação imobiliária ficaram à espera de uma regulamentação. Questões básicas relativas à mobilidade urbana deixaram de ser tratadas, mas repetidas discussões foram efetuadas sobre a necessidade primordial de regulamentar a utilização de drones na cidade. ${ }^{1}$

Como pode se observar, apesar de algumas variações, na grande maioria dos municípios, a possibilidade de uma participação efetiva da população na elaboração e processo de implementação dos planos diretores vem enfrentando um conjunto de resistências e condições pouco favoráveis, como o poder dos interesses imobiliários e a reduzida aderência dos gestores locais aos princípios e disposições do Estatuto da Cidade, as dificuldades de mobilização e organização da sociedade civil, a cultura política e os impasses ao avanço da democratização no Brasil.

Discutindo essas condições, vale lembrar que, como bem ressaltam Logan e Molotoch (1987), nas sociedades capitalistas, a produção do espaço urbano envolve um conflito permanente entre o seu valor de uso e o seu valor de troca, que opõe, de um lado, os moradores da cidade, interessados sobretudo na defesa da sua qualidade de vida, e, de outro, uma coalisão de interesses comandada pelo capital imobiliário, que visa a um maior retorno financeiro e à ampliação dos seus lucros, com a transformação da cidade em uma espécie de "máquina de crescimento".

Como se sabe, ao longo do processo de urbanização do Brasil, os interesses dessa coalisão sempre foram amplamente dominantes. Além disso, com as transformações contemporâneas do capitalismo, a aceleração dos fluxos de capital associados à globalização, as políticas de liberalização econômica e um novo enfoque da governança que se rege pelos princípios de subsidiariedade estatal e ênfase nos mecanismos de mercado, as cidades assumiram um papel ainda mais relevante no processo de acumulação.

Com isso, sob a influência do Banco Mundial e de outras agências multilaterais no Brasil e em vários países da América Latina, o denominado empreendedorismo urbano vem substituindo a matriz de planejamento racionalista e funcionalista, pautando a governança urbana. Discutida por autores como Harvey (2005), Vainer (2002), Maricato (2002) e Mattos (2010), essa governança se inspira em conceitos e técnicas oriundas do planejamento empresarial e compreende a cidade, principalmente, como sujeito ou ator econômico e vê, como eixo central da questão urbana, a busca de uma competitividade orientada para atrair os capitais que circulam no espaço sem fronteiras do mundo globalizado, de forma a ampliar os investimentos e as fontes geradoras de emprego. Para o alcance desses objetivos, competiria, aos governantes locais, utilizar estratégias de promoção e "venda" da imagem da cidade, considerar as expectativas e demandas do mercado e criar um ambiente favorável e atrativo para os investidores. 
Como ressalta Mattos (2010), essas orientações favorecem especialmente os investimentos imobiliários, com os quais os governantes locais vêm tendendo a negociar as condições para a sua maior expansão, incluindo, entre elas, a flexibilização das normas relativas ao parcelamento e uso do solo e aos códigos de edificação antes estabelecidos. Com restrição dos recursos e inversões estatais, a ênfase nos mecanismos de mercado e a nova primazia do capital imobiliário (acentuada pelo seu atual porte e perfil e pela sua maior capacidade de intervenção no espaço das cidades), o desenvolvimento urbano consolida-se, agora, dentro de uma lógica mais estritamente capitalista, deixando em segundo plano ou até contrariando as necessidades e as demandas mais amplas da população. E, como não poderia deixar de ser, isto se reflete nas orientações e disposições dos planos e em obstáculos à participação.

Além disso, embora, com a redemocratização do País, a Constituição de 1988 tenha afirmado a possibilidade de exercício da democracia direta como um dos princípios fundamentais da República (Vitale, 2004, Avritzer, 2016), com a participação da população e de organizações representativas dos vários segmentos da sociedade na formulação, execução e fiscalização das políticas públicas, complementando a democracia representativa, esse princípio vem enfrentando significativas dificuldades e resistências para se efetivar.

Analisando a experiência democrática recente, Avritzer (2016) defende a tese de que o Brasil é um país com uma democracia forte e consolidada. Essa constatação se sustenta, do ponto de vista histórico (as últimas décadas foram mais estáveis, historicamente, do que o período de 1946-1964), quando comparamos
- Brasil com, por exemplo, a Argentina e o Chile. O referido autor considera que, do ponto de visa econômico, social e político, o País conseguiu romper com os limites do procedimentalismo, tendo alcançado avanços significativos no combate a desigualdade, pobreza e melhoria da qualidade de vida da população. ${ }^{2}$ Entretanto, afirma Avritzer (ibid.), existem "impasses" na democracia brasileira, limitações que se traduzem em um certo mal-estar, resultado de expectativas não devidamente correspondidas, de promessas não cumpridas. Dentre os impasses relacionados estão os limites do presidencialismo de coalizão, os paradoxos do combate à corrupção, a perda de status das camadas médias, o papel do judiciário na vida política e limites da participação popular na política (ibid.).

Particularmente em relação a essa última questão, Avritzer (2016) relembra que o Brasil institui, a partir dos anos 1980 , um novo padrão de participação social, institucionalizado com a constituição cidadã de 1988. A luta pela redemocratização e o fim da ditadura militar criaram um cenário favorável à institucionalização da participação, e ele considera os anos 1990 como um tempo de bons exemplos de participação política, com limitações que só vão aparecer em 2013, sendo uma das mais relevantes o seu caráter seletivo, que se concentra, setorialmente, nas políticas sociais, inexistindo ou sendo rarefeita em políticas e projetos de infraestrutura, mobilidade e transporte. Nesse contexto, afirma Avritzer, é que se desenrolam os conflitos entre as mobilizações que tomaram as ruas, a participação "espontânea", não organizada partidariamente, e a institucionalizada. Emerge, então, uma "nova direita", com capacidade de mobilizar setores conservadores e pautar a arena política, 
direita, que, segundo Avritzer, pode comprometer o projeto político de caráter participativo, de esquerda, no Brasil.

Essa análise, esclarecedora em alguns aspectos, não aprofunda os distintos significados políticos que a participação adquire ao longo das duas últimas décadas no País. Avancemos nessa reflexão, com o objetivo de melhor compreender as aporias da participação da experiência aqui analisada, recorrendo ao diálogo que Avritzer trava com Paulo Arantes (2014) e com Marcos Nobre (2013), que discutem em publicações recentes os significados da democracia e da participação nos tempos de hoje. A referência ao trabalho de Arantes por Avritzer toca em um ponto essencial da sua tese de que o País tem hoje uma democracia consolidada. Recorrendo aos clássicos, Arantes parte do pressuposto de que existe uma incompatibilidade entre democracia e capitalismo e que as políticas de participação em curso são formas de cooptação, e isso estaria se manifestando de forma plena no Brasil nas últimas décadas. Para o autor, a cidadania insurgente, fruto do processo de luta contra a ditadura, teria dado lugar a uma cidadania regulada, contida nos marcos do capitalismo periférico e administrada pelo Partido dos Trabalhadores (Arantes, 2014).

Avritzer contrapõe-se à abordagem de Arantes, defendendo o processo de institucionalização ocorrido ao longo da última década, a legitimidade da ação estatal e o movimento de incorporação da participação nos processos de construção e implementação de políticas públicas, afirmando que "nada existe de errado com a regulação legal da cidadania, desde que seja produtora da inclusão social e igualdade política" (Avritzer, 2016, p. 25). Criticando Arantes (2014), ele considera que o argumento da cooptação da participação transforma as virtudes da democracia brasileira em dificuldades. Adicionalmente, ele afirma que, ao rejeitar o pressuposto de que a democracia, através da soberania popular, pode solucionar as injustiças gestadas pelo capitalismo, Arantes coloca-se no campo da "fé política". Mas, afinal, por que, ao estabelecer uma relação de conflito entre democracia e capitalismo na periferia do sistema, Arantes estaria no campo da fé e não da teoria? O que assegura, ao argumento de Avritzer, o estatuto de teoria, de ciência e não de "ideologia" ou de "fé?" Esse não seria um argumento ad populum ou apelo à galeria de quem tem a pretensão, não tão ingênua afinal, de falar em nome de princípios pretensamente universais como os científicos? Mas o que importa aqui é exatamente entender a natureza e a qualidade da participação na nossa mais ou menos consolidada democracia, e, buscando aprofundar seus argumentos, Avritzer (2016) vai ao encontro de Nobre (2013), do conceito de peemedebismo.

Nobre (ibid.) molda esse conceito em uma tentativa de compreender a natureza da cultura política brasileira e, assim, explicitar os limites e avanços do nosso processo democrático e participativo. Seu ponto de partida é exatamente a seguinte questão: "como o sistema político consegue manter sob controle os conflitos de uma sociedade assim desigual?". Ele defende a tese de que esse controle, nos dias de hoje, tem como um dos seus pilares uma cultura política instituída a partir dos anos 1980, "que blindou o sistema político contra as forças sociais de transformação". Ele faz uma retrospectiva histórica cujo ponto de inflexão é a luta contra a ditadura, passando pela redemocratização até os dias atuais, para definir o que qualifica como "peemedebismo", 
ou seja, a constituição de um bloco de poder, cuja característica marcante é a relação (atávica) com as forças políticas hegemônicas e a instituição de um sistema de coalização como ponto de veto. Como ressalta o autor, essa não é exatamente uma característica de um partido político em específico, mas uma forma particular de fazer política, que consiste na construção de alianças e acordos de modo a assegurar benéficos da máquina pública, eliminar e controlar o dissenso. Trata-se, substancialmente, de "estar no governo seja qual for o governo e seja qual for o partido" e de criar um "conjunto de regras de arbitragem de conflitos" em um "sistema de vetos hierarquizado" (ibid., p. 42). O peemedebismo caracteriza-se, então, por elementos como o governismo, a criação da governabilidade, a construção de hegemonia e a eliminação ou neutralização das oposições (ibid., p. 14), elementos através dos quais o capitalismo periférico consegue manter sob controle os conflitos de uma sociedade assim desigual.

O peemedebismo seria, então, uma forma particular de regulação da ação política através da qual se assegura a reprodução de relações de poder historicamente hegemônicas. Nobre parte de um pressuposto diferente do de Avritzer (2016): a passagem do governo de Fernando Henrique Cardoso para o de Luiz Inácio da Silva foi a primeira alternância de poder não traumática, e esse fato histórico consolida o processo de redemocratização no País. Entretanto, formalidades cumpridas, "a democracia no País, tudo somado, é ainda muito pouco democrática de fato". E isso se explica por não termos conseguido construir, ainda, uma cultura democrática capaz de mudar a "forma de vida", "uma cultura política pluralista, organizando o próprio cotidiano das relações entre as pessoas". Apesar dos avanços nas últimas décadas, o fato é que, para o referido autor, temos uma "cultura política de baixo teor democrático" em um País profundamente desigual e com sérios limites ao processo de participação política (Nobre, 2013, p. 9).

Avritzer (2016) critica a tese do peemedebismo afirmando que Nobre não errou no conceito, mas pecou na "calibragem". Ele explica bem os entraves do processo de construção democrática, mas esquece os seus sucessos ou os qualifica como concessão ou como práticas típicas do peemedebismo. De modo enfático, Avritzer reafirma: "a democracia no Brasil funcionou bem, seja na sua capacidade de produzir decisões, seja na sua capacidade de ampliar a inclusão social" (Avritzer, 2016, p. 27). Seus limites estariam sendo determinados pelo presidencialismo de coalizão e pelo ineficiente combate à corrupção, aspectos que estão relacionados, mas que não se confundem.

Os trabalhos de Evelina Dagnino (2002), com os conceitos de confluência perversa e de projeto político, e de Francis Wolf (2007), com o debate sobre o esquecimento da política, agregam elementos relevantes a essa discussão. Em primeiro lugar, é preciso problematizar a tese defendida por Avritzer, de que a participação se processa como um contínuo ao longo da construção democrática recente e que as suas limitações decorrem do seu caráter setorializado. Recorrendo à noção de confluência perversa, é preciso registrar que o que de fato confere uma dimensão substantiva ao processo participativo é a dimensão do poder e o projeto político. 0 modelo neoliberal, nos anos 1990, assim como o projeto de cunho democratizante tinham como um dos seus requisitos a participação. Entretanto, a participação no modelo neoliberal é um requisito 
para redução do Estado e a transferência de responsabilidades, enquanto, no projeto democratizante, estaria ou deveria estar associada a um projeto de descentralização de poder, de democratização do Estado e da sociedade, com implicações de natureza econômica, social e política. A noção de confluência perversa de Dagnino (2002) refere-se, exatamente, ao fato de que o que diferencia ou deveria diferenciar essas duas perspectivas e possibilidades de participação é o projeto político, conceito que ela traz de Gramsci. Em segundo lugar, poderíamos considerar que os limites concretos da participação no nosso recente processo de democratização nos reportam à interpenetração de projetos políticos, entre forças políticas que, historicamente, estiveram em campos e arenas distintas. Esse tipo de constatação nos aproxima dos argumentos de Nobre (2013) sobre a peemedebização da política (sem esquecer os avanços e as conquistas, como nos lembra Avritzer), como também do esquecimento da política e da fetichização da técnica em tempos de retomada do modelo neoliberal, como nos lembra Wolf (2007).

\section{Reflexões a partir da experiência de Salvador}

A experiência de elaboração dos Planos de Desenvolvimento Urbano (PPDU) de Salvador é bastante ilustrativa das limitações estruturais da construção democrática no País, com especial ênfase no atual momento de redefinição do cenário político. Salvador é uma cidade marcadamente pobre e desigual, com uma estrutura produtiva predominantemente terciária e um PIB inferior ao de cidades como Fortaleza e Recife. Os históricos problemas de desenvolvimento e as condições de vida, trabalho e pobreza de sua numerosa população não favoreceram a constituição de uma classe trabalhadora forte e organizada, de movimentos sociais mais dinâmicos e articulados e de uma sociedade civil mobilizada no que se refere à gestão da res publica, e isso se reflete nos perfis das suas organizações populares e nas suas formas de manifestação. Associa-se, a esses traços, o longo domínio político de lideranças e de uma oligarquia conservadoras e autoritárias, fechadas ao diálogo com a sociedade civil e à participação.

Estudo realizado por Avritzer (2007) comparando os processos de participação em Fortaleza, Salvador e Recife, constata que Pernambuco é o estado que apresenta uma participação mais densa e a Bahia, o estado onde o associativismo é mais fraco, especialmente no caso de Salvador e no que diz respeito à participação nas questões relativas à gestão pública (ibid., p. 45). Confirmando as colocações do autor, o caso de Salvador é bastante ilustrativo do processo de esvaziamento da participação popular e de como a noção de peemedebismo contribui para a compreensão de como são tomadas as decisões sobre a gestão e o desenvolvimento da cidade, conforme fica patente pela experiência da elaboração, discussão e aprovação dos seus planos diretores nos últimos anos, com ênfase no Plano aprovado em 2016, objeto mais específico deste trabalho. 


\section{A participação no PDDU de 2004 e de 2008}

A revisão do Plano Diretor institucionalizado em 2004 teve início em 1998, durante a gestão do prefeito Antônio Imbassahy, integrante do grupo político que há muitos anos dominava o poder nas esferas estadual e municipal. Esse trabalho de atualização arrastou-se por um longo tempo, e foi questionado, sobretudo, pela falta de transparência e pela forma autoritária como se deu a sua elaboração. A proposta apresentada pelo executivo tinha uma linguagem pouco accessível e privilegiava os interesses do capital imobiliário; as informações necessárias para sua discussão não foram disponibilizadas, e as audiências para essa discussão foram pouco divulgadas, não havendo espaço para uma participação. Embora isso não impedisse sua aprovação pela Câmara de Vereadores, organizações da sociedade civil acionaram o Ministério Público para entrar com uma ação civil pública contra o plano, e essas pressões levaram a nova gestão municipal a decidir pela sua revisão.

Como analisa Nascimento (2008), a sucessão municipal, em 2005, colocou a expectativa de uma gestão mais democrática e avançada, pois o novo prefeito (eleito no segundo turno contra o domínio tradicional do carlismo, com o apoio de grupos conservadores, mas, também, de forças progressistas e partidos de esquerda) assumira publicamente o compromissos de rediscutir o PDDU, incorporando os princípios do Estatuto e a participação da sociedade civil na sua elaboração e implementando, na cidade, um projeto de desenvolvimento sustentável, e até adotou, como símbolo de sua gestão, o slogan de "Salvador: Prefeitura de Participação Popular".
Contudo, a promessa de um "outro tempo" na relação do poder local com a sociedade civil e com os movimentos populares não passou da retórica eleitoral. A aliança com as forças e os partidos progressistas terminou sendo rompida, e o alcaide nunca se propôs, efetivamente, a mudar os padrões excludentes do desenvolvimento urbano, a contrariar os interesses do capital imobiliário ou a adotar novas práticas e orientações, como ficou patente ao longo da referida revisão.

Sob a responsabilidade da Secretaria de Planejamento e Meio Ambiente do Município (Seplam), a referida gestão teve início com um amplo debate sobre o conteúdo e as propostas do Plano que havia sido aprovado na administração anterior, o que se seguiu a elaboração de uma minuta e de uma nova proposta de Projeto de Lei, encaminhado ao legislativo municipal em agosto de 2007. Segundo registros da equipe técnica responsável, foram realizadas várias atividades com o objetivo de inserir a sociedade civil no processo de revisão do Plano, a exemplo de audiências públicas e reuniões, nas diversas Regiões Administrativas e com o Conselho Municipal de Desenvolvimento Urbano - Condurb, e de dois seminários orientados para a discussão da economia local e regional. Para esses eventos, foram convidados representantes das organizações de moradores das Regiões Administrativas (RAS), entidades da sociedade civil, coordenação das administrações regionais, representações empresariais e lideranças partidárias. Ademais, a Superintendência do Meio Ambiente, então administrada pelo Partido Verde, também constituiu um grupo de trabalho que reuniu representantes do Ministério Público, de sindicatos e universidades, de organizações empresariais, entidades ambientais e movimentos 
comunitários, entre outros, com o objetivo de discutir questões ambientais e apresentar propostas que assegurassem a preservação e a recuperação das áreas verdes e da orla de Salvador, uma das grandes preocupações dos grupos ambientalistas.

Mas, apesar dessas iniciativas, o processo de revisão do PDDU foi pouco divulgado e participativo, e a sociedade civil não teve possibilidade de exercer o necessário controle na reta final de sua aprovação. As propostas resultantes dos fóruns e discussões realizadas não foram incorporadas no novo Projeto de Lei, prevalecendo os pontos de vista da equipe técnica da prefeitura e os interesses mais diretos e imediatos de grupos imobiliários, que se mobilizaram intensamente na reta final da aprovação. Em um contexto de reduzida organização e mobilização, não houve investimentos e incentivos que estimulassem a participação. A grande maioria da população sequer tomou conhecimento do processo de revisão do Plano (como não tomara da sua anterior aprovação), conforme amplamente divulgado pela mídia local. Reuniões e audiências públicas contaram com poucos participantes, e tanto a restrita divulgação do Projeto como a sua linguagem técnica e pouco acessível contribuíram para tornar as reuniões desinteressantes e cansativas. A mais concorrida não contou com mais do que noventa participantes, ${ }^{3}$ e, no seu conjunto, elas congregaram poucas pessoas.

Além disso, a estreita articulação entre a prefeitura e o mercado imobiliário expressou-se na elaboração de um Plano orientado para atender aos interesses do referido mercado, flexibilizando e alterando normas e instituindo mecanismos para facilitar (ainda mais) a apropriação, por esses setores, da mais-valia urbana. Ainda que tenha incorporado aspectos relativos à carência de infraestrutura e serviços básicos, a habitação popular ou o transporte e mobilidade, o Plano teve como foco a modificação dos parâmetros construtivos e a elevação do gabarito na "área nobre" da cidade, como desejavam os empreendedores imobiliários.

Bastante questionado, o referido texto foi aprovado pela Câmara na calada da noite, com muitas emendas consideradas suspeitas, que sequer chegaram a ser lidas antes da sua aprovação. 0 texto terminou sendo objeto de uma ação por parte do Ministério Público, entre outros motivos porque desrespeitava as disposições do Estatuto no que tange à participação popular. Mas esse processo não teve efeitos práticos, pois o Ministério Público só ganhou a referida ação quatro anos depois, quando o Plano já tinha sido revisado, com a mesma orientação. 0 eixo da revisão continuou a ser um claro incremento nos parâmetros urbanísticos de aproveitamento do solo (aumentando a intensidade de ocupação por zonas), sem apresentar estudos técnicos que justificassem as mudanças ou, ao menos, avaliassem os seus impactos em termos urbanos, sociais e ambientais (Carvalho, 2013). O PDDU terminou sob judice, mas, apenas dois meses antes do fim do seu mandato, o prefeito enviou ao legislativo um conjunto de propostas que recuperava as suas disposições e as da Lei de Ocupação e Uso do Solo - Louos, aprovada no seu mandato (que se encontravam sob judice no Tribunal de Justiça da Bahia, em decorrência de outra Ação Direta de Inconstitucionalidade proposta, mais uma vez, pelo Ministério Público), tentando legalizar e institucionalizar as transformações urbanísticas perseguidas ao longo da sua gestão. 


\section{A participação no PDDU de 2016}

A elaboração do PDDU na gestão do prefeito Antonio Carlos Magalhaes Neto (2012-2016) não fugiu à regra instituída no processo anteriormente referido. Com uma nova gestão e um novo grupo político à frente da prefeitura (afinal, não tão novo, uma vez que se tratava da volta de membros da família de Antônio Carlos Magalhaes), o Plano Diretor elaborado em 2008 foi objeto de mais uma nova revisão, entre os anos de 2015 e 2016, com trajetória e resultados que não se mostraram muito diferentes das experiências anteriores.

Porém, dessa vez, ele foi apresentado como parte de uma iniciativa mais ampla e ambiciosa, o denominado "Plano Salvador 500 ", definido como um plano estratégico para os próximos trinta e cinco anos (quando a capital baiana completará 500 anos), enquanto o Plano Diretor constituiria em um instrumento de médio prazo, devendo ser revisado de oito em oito anos, e focado nas políticas de desenvolvimento urbano. ${ }^{4} E$, embora continuassem pouco permeáveis às disposições do Estatuto relativas à democratização da gestão urbana, as contestações e judicializações dos planos anteriores e as pressões do mercado imobiliário por "segurança jurídica" levaram a prefeitura a se preocupar mais, dessa vez, com as exigências legais e com o ritual da participação.

As primeiras atividades do Plano iniciaram-se em agosto de 2014, e, em dezembro, a Prefeitura contratou a Fundação Instituto de Pesquisas Econômicas - Fipe para elaborar os estudos técnicos necessários para embasar a revisão do Plano e da Louos e para subsidiar o "Plano Salvador 500". Em 2015, a administração municipal elaborou um Plano de Mobilização e Participação Social - PMPS, considerando, como sujeitos desse processo, os interessados que afetassem ou pudessem ser afetados pelo plano, devendo participar "não apenas as lideranças da sociedade, mas qualquer cidadão interessado que não se sinta representado ou não tenha acesso às estruturas de poder" (PMS, 2015, pp. 2 e 3).

As estratégias de participação propostas pelo PMPS envolveram um conjunto de atividades, qualificadas como de "formação", de "consulta", de caráter "técnico" e de caráter "político", com destaque para: (1) oficinas de bairro nas quais a coordenação do Salvador 500 se propunha a trabalhar "conceitos básicos de cidadania, meio ambiente e desenvolvimento urbano, a partir da incorporação de vivências e de experiências cotidianas dos participantes no seu próprio ambiente, ampliando o olhar dos cidadãos sobre a cidade"; (2) fóruns temáticos com especialistas convidados para discutir questões como desenvolvimento econômico, mobilidade urbana ou meio ambiente; (3) audiências públicas para a discussão do Projeto de Lei do PDDU, a ser enviado à Câmara de Vereadores; (4) audiências públicas realizadas na Câmara antes da votação desse Projeto (ibid., p. 3).

No total, foram realizadas 29 oficinas de bairro (em dois diferentes ciclos), alguns fóruns temáticos, 14 audiências públicas, antecedendo o envio do Projeto de Lei do PDDU ao legislativo, e mais outras 19 no âmbito da Câmara, mas sem que isso assegurasse a efetividade do processo de participação (ibid., p. 3). Conforme vários registros em atas e depoimentos nas entrevistas, a prefeitura fez uma divulgação que, no mínimo, pode ser considerada apressada e insuficiente das referidas reuniões. Como assinala Santos (2016), o primeiro ciclo 
das oficinas de bairro resumiu-se basicamente à colocação de outdoors em algumas áreas da cidade, com dizeres genéricos nos quais não constavam, por exemplo, a data e o local das oficinas. ${ }^{5}$ As audiências também não tiveram a necessária publicização. Informações sobre suas datas e locais ficaram restritas ao Diário Oficial do Município e ao site do Plano, e o intervalo entre a sua realização variou de oito meses (entre a primeira e a segunda) a algumas poucas horas (caso da quarta e da quinta audiências, realizadas em turnos diferentes de um mesmo dia). A utilização de meios de comunicação de massa (no caso o rádio) só começou a ocorrer no meio do segundo ciclo dessa atividade, por pressão do grupo Participa Salvador.

Segundo registros em atas e entrevistas, as atividades foram realizadas em horários em que a maioria das pessoas estava trabalhando, e tanto a postura autoritária como a metodologia da coordenação do Plano mostraram-se adversas à participação. Nas oficinas e nas audiências públicas, as exposições do Plano foram tratadas como uma espécie de aulas, pressupondo uma diferença de níveis entre os dois polos do processo: um polo ativo, representado pela coordenação do Plano, que difundia informações, e um polo passivo, que as recebia. ${ }^{6}$ Tais problemas foram assinalados principalmente por participantes das camadas populares, a exemplo de um ex-coordenador da Federação das Associações de Bairros de Salvador - Fabs, ressaltando que:

A mobilização da prefeitura foi precária. O governo municipal poderia ter acionado a mídia local para mobiliar o conjunto das entidades da sociedade $e$ a população da cidade. Isso não foi feito. Em relação à metodologia, também, o município falhou. Primeiro em não discutir minimamente um procedimento metodológico e em segundo por apresentar um método ineficiente e manipulador. Me refiro às chamadas audiências com os bairros que resumiram a discutir problemas de "varejo" proporcionando um ambiente populista de listagem de pequenas obras nos bairros. Passando, portanto, ao largo das discussões essenciais de estruturação e planejamento da cidade. Serviu para construir uma hegemonia política entre as lideranças de bairros num estilo coronelato com verniz de modernidade. As intervenções de entidades que produziram acúmulo de debate técnico, acadêmico e político, como IAB, Sindicato de Engenheiros, Sindicato de Arquitetos, Grupos de pesquisas de instituições universitárias da UFBA, Uneb, IFBaiano, Fabs, entidades ambientalistas, entidades da defesa da mulher, luta antirracista, LGBT, foram desconsideradas, num processo de discussão que primou pela atitude de desqualificação do interlocutor na relação entre prefeitura e sociedade. (Entrevista 1 - Representante da Federação das Associações de Bairros de Salvador - Fabs, 2017)

Na fase das audiências, informações básicas para o debate foram divulgadas através de relatórios complexos e com uma extensão entre 300 a 500 páginas, disponibilizados com uma antecedência de cerca de quinze dias, suscitando questionamentos quanto à viabilidade de sua leitura e compreensão em um tempo tão curto. Nessas circunstâncias, não chega a ser surpreendente que boa parte do tempo dessas reuniões tenha sido dedicado a leitura e discussão dos atos e a disputas relacionadas com o próprio processo participativo, sua metodologia e efetividade. 
As audiências públicas tiveram início em março de 2015, e, na primeira realizada, duas reivindicações marcaram o encontro: a primeira foi a demanda apresentada por membros da plenária para que o prefeito convocasse o Conselho Municipal de Salvador; ${ }^{7}$ a segunda foi que a prefeitura buscasse, na condução das discussões dos trabalhos do Plano, privilegiar "a clareza e objetividade das comunicações", de modo a permitir a compreensão do conteúdo apresentado, uma vez que estariam ali presentes "pessoas com formação técnica e sem essa formação" (PMS, Ata da Audiência Pública n. 1, 10 de agosto de 2015, pp. 1-3).

Na segunda Audiência, realizada em 15 de abril de 2015, representantes do Movimento Participa Salvador solicitaram a suspensão e se retiraram, alegando que havia menos de cinquenta participantes, que os movimentos de bairro estavam ausentes, que as "circunstâncias do dia" (marcado por manifestações populares em todo o País e por uma greve de ônibus) haviam impedido a chegada das pessoas e que "a discussão merecia uma maior representatividade". Apoiando essa demanda, uma outra participante, estudante universitária, afirmou não ter visto nenhuma propaganda da audiência e que, por isso, as pessoas não estavam sabendo. Em relação às Oficinas de Bairros, ela declarou que: "não houve discussão ou explicação em torno do PDDU"; ademais, "quando alguém perguntava ou pedia ajuda aos facilitadores, esses agiam como 'procuradores' da Prefeitura, dando explicações que isentavam a prefeitura dos problemas apontados pelos moradores". Ela assinalou, ainda, que para muitas pessoas, "era a primeira vez que ouviam falar em Plano Diretor e leis de uso do solo, ou até mesmo análise de pontos fortes e fracos das localidades". Para terminar, considerou ser possível que "essa gestão triIhe o mesmo caminho que a anterior" (PMS, Ata da Audiência Pública n. 2, em 15 de abril de 2015, pp. 1-6). Ainda assim, apesar desse e de outros protestos, o coordenador dos trabalhos, secretário municipal de Salvador, deu continuidade à sessão, alegando terem sido cumpridos todos os ritos de convocação com tempo suficiente e a necessidade de respeito aos presentes.

Questões relativas à sistemática dos debates e à representatividade da participação se repetiram ao longo das demais audiências públicas. Na audiência que foi realizada no dia 6 de junho de 2015, por exemplo, alguns dos participantes manifestaram sua "angústia" em decorrência do pequeno número de moradores presentes nessas atividades, solicitando informações sobre o plano de comunicação da prefeitura, de modo a tornar claros os recursos aplicados e o alcance das ações de comunicação. O representante oficial assinalou, então, que as audiências públicas não constituíam momentos de interação com os movimentos sociais e que, para isso, fora desenhado um outro tipo de evento, as oficinas de bairro, que penetrariam melhor nos bairros e que, de fato, auxiliariam o contato com suas lideranças (PMS, Ata da Audiência Pública n. 6, em 6 de junho de 2015, pp. 1-6).

Ressaltando a dificuldade de computar o número real de pessoas presentes às oficinas por ter sido comum o "entra e sai" ou a mera assinatura na lista de presença, Santos (2016) estima ter havido uma média de cinquenta e cinco pessoas no primeiro ciclo e de cinquenta e seis no segundo ciclo das oficinas; embora tenha havido casos, como o da oficina realizada em Pau da Lima, em que, no último ciclo, não estivessem presentes mais que dezessete 
moradores. Nas audiências públicas, houve maior variação, com um número mais reduzido de participantes da 1 à à $8 \underline{a}$ audiência, quando se deram a definição da metodologia e a apresentação dos estudos técnicos, e uma elevação significativa desse número da 9ạ a 14a audiências, dedicadas à discussão da minuta do Projeto de Lei do PDDU. Efetivamente, a discussão do conteúdo do Plano Diretor de Desenvolvimento ocorreu nas audiências públicas datadas de 3 de outubro de 2015 (9a), 5 de outubro de 2015 (10a ), 6 de outubro de 2015 (11) $), 7$ de outubro de 2015 (12a) , 24 de outubro de 2015 (13a), sendo a discussão encerrada em 26 de outubro de 2015 (14a) ), ou seja, em seis sessões. A audiência mais esvaziada foi a segunda, por motivos já mencionados, e a mais cheia a 14ạa que congregou 275 participantes. Já os fóruns temáticos alcançaram entre cento e cinquenta a duzentas pessoas, embora tenham se assemelhado a seminários acadêmicos ou a congressos profissionais no seu formato e metodologia, com uma apresentação e um conteúdo bastante técnicos, que atraíram um público muito específico e diferenciado.

A experiência de discussão e aprovação do PDDU na Câmara de Vereadores de Salvador passou por questões e dilemas semelhantes aos anteriormente relatados ao longo das audiências realizadas pelo executivo municipal, quais sejam: a demanda de entidades e de alguns vereadores de que o Regimento das Audiências fosse debatido em plenária e a falta de representatividade de entidades da sociedade civil, de participação dos moradores e mesmo de vereadores da casa (as audiências, de uma maneira geral, contaram com participação em plenário de funcionários da própria gestão). Na primeira Audiência, datada de 16 de dezembro de 2015, um dos vereadores, chamou a atenção para que o debate na Câmara de Vereadores não repetisse os erros ocorridos com a experiência das audiências promovidas pela prefeitura: "a Câmara deveria aperfeiçoar o processo havido na Prefeitura mas [...], ao contrário, estava ocorrendo um retrocesso" (Câmara de Vereadores, Ata da Audiência Pública n. 1, em 16 de dezembro de 2015, p. 3).

O secretário de planejamento da prefeitura defendeu a condução dos trabalhos em curso afirmando que "[...] este seria o PDDU mais participativo do país". Em nome do prefeito, registra que o PDDU deveria "refletir um consenso dentro da sociedade e destacou o papel da Casa na consolidação dessa meta" (Câmara de Vereadores, Ata da Audiência Pública n. 1, em 16 de dezembro de 2015, p. 3). Essa posição foi reiterada várias vezes pela equipe técnica como também por vereadores da base política do prefeito (Câmara de Vereadores, Ata da Audiência Pública n. 2, em 23 de fevereiro de 2016, p. 1).

Vereadores à frente dos trabalhos de coordenação na Câmara chamaram a atenção para a inovação que as Audiências "Devolutivas" incorporaram na discussão do PDDU na Câmara (são Audiências nas quais os coordenadores dão retorno em relação às sugestões apresentadas). Consideraram que, através desse mecanismo, estaria havendo um "empoderamento da sociedade" e que eles se sentiriam vitoriosos "por estarem na metade do processo das audiências, com participação popular inclusive digital". Segundo registro da coordenação dos trabalhos na Câmara, um atestado do caráter democrático e representativo dos trabalhos teria sido a indicação de um vereador do PT, como presidente da Comissão, e de 
um outro do DEM, como relator (Câmara de Vereadores, Ata da Audiência Pública n. 16, em 25 de abril de 2016, p. 2).

Durante as audiências de "Devolução", um aspecto merece ser destacado: a distinção, realizada pelos coordenadores dos trabalhos entre conteúdos que seriam de natureza "técnica" e outros qualificados como "políticos". Como registrado na Audiência n. 14, é preciso observar que "as respostas devolutivas não abordavam o mérito das propostas, mas, apenas sua adequação". Essa postura se repetiu ao longo de várias audiências. Ali, naquele espaço, o que estaria em discussão seriam os aspectos propriamente "técnicos". Membro da equipe técnica da Câmara, justificando a posição adotada sobre um aspecto polêmico do Plano ressaltou: que "a Comissão Técnica avalia a viabilidade técnica da sugestão, e não o mérito, [...] destacando que não estava a analisar a justeza das reivindicações", devendo isso ser definido em outro fórum (Câmara de Vereadores, Ata da Audiência Pública n. 14, em 7 de abril de 2016, pp. 7-11).

Mas quem decide sobre o conteúdo do Plano Diretor em Salvador? Questionados, por exemplo, sobre a participação do ConseIho Municipal no processo de sua aprovação, membros do corpo técnico afirmaram que "a deliberação pode ocorrer em vários níveis" e citando a resolução n. 34 do Ministério das Cidades, considerando que "compete ao Conselho emitir orientações e recomendações no intuito de aconselhar, mas não com caráter deliberativo" (Câmara de Vereadores, Ata da Audiência Pública n. 15, em 14 de abril de 2016, p. 7). Quem, então, decide sobre o conteúdo do plano são os vereadores. Mas quais vereadores? Em primeiro lugar, ao longo das audiências foi decidido, pela Comissão de
Constituição, Justiça e Redação Final (CCJ), que não seriam aceitas emendas apresentadas em Plenário quando da votação do Plano (Câmara de Vereadores, Ata da Audiência Pública n. 13, em 28 de março de 2016, p. 1). Em segundo lugar, as contribuições apresentadas não passaram, de fato, pelo crivo das audiências. A título de exemplo, um dos vereadores criticou o fato de suas emendas não terem sido acolhidas, como a emenda supressiva referente à Linha Viva, afirmando que essa via iria criar pedágio dentro da cidade e ocasionaria desapropriação em massa, além de desmatamento" (Câmara de Vereadores, Ata da Audiência Pública n. 18, em 23 de maio de 2016, p. 6).

Ainda nessa audiência foram registradas reclamações sobre o esvaziamento das últimas reuniões do Plano, com a ausência das "autoridades", a exclusão das periferias, além de questionamento de vários aspectos do seu conteúdo, relevantes, e que não passaram por um efetivo debate. Finalmente, qual a participação do Conselho da Cidade nesse processo? $\mathrm{Na}$ audiência datada de 30 de março, marcada para apresentar o plano ao Conselho da Cidade, os conselheiros não compareceram: após a leitura da relação dos conselheiros e constatando a ausência deles, a audiência foi encerrada: "Novamente, procedeu à leitura da lista contendo o nome dos conselheiros e, mais uma vez, sendo constatado não haver algum presente, considerou que o encontro perdia seu objeto e declarou encerrada a audiência" (Câmara de Vereadores, Ata da Audiência Pública n. 19, em 30 de maio de 2016, pp. 1-2).

$E$, afinal, para que serve esse Plano? Segundo depoimentos registrados em atas e entrevistas, depende do ponto de vista e dos interesses. Segundo outro participante do processo de discussão, "se o PDDU precisasse de 
horizontes temporais, a lei n. 7.400 'estaria no chão'”. Lembrou que o Plano de Saneamento Básico do professor Luis Roberto Moraes foi anexado aos Planos de 2004 e 2008, e nada dele foi realizado, e, agora, exatamente o mesmo Plano foi acolhido na minuta em discussão. O Plano tem horizonte para atender aos interesses dos seus formuladores (Câmara de Vereadores, Ata da Audiência Pública n. 8, em 3 de março de 2016, p. 9).

Em suma, a pouca permeabilidade do poder local ao processo em discussão, a restrita divulgação de informações e documentos, a utilização de uma linguagem pouco acessível ao cidadão comum, a metodologia e a sistemática das reuniões dificultaram a compreensão e a discussão mais amplas do projeto e das questões maiores em jogo. Problemas, propostas e emendas apresentadas pelos participantes foram desqualificados ou desconsiderados. Conforme depoimento de uma outra Vereadora:

A tramitação na Câmara, a exemplo do que ocorreu no executivo, também foi complicada. O Legislativo não divulgou suficientemente, fez um cronograma de audiências intensivo, com duas ou até três audiências na mesma semana, dificultando muito a participação. A maioria das audiências ocorreu nas dependências da Câmara quando deveriam ter sido descentralizadas. Não forneceu elementos à população para possibilitar uma participação efetiva, a exemplo de cartilha com informações básicas sobre PDDU. Raríssimas propostas apresentadas em audiência foram incorporadas ao projeto. Para agilizar, o presidente formou uma comissão especial juntando as comissões de Constituição e Justiça, Orçamento e Planejamento Urbano, para votar o projeto, coisa que não teve apoio regimental. Não incorporou efetivamente os urbanistas no processo. As emendas incorporadas ao texto foram selecionadas exclusivamente pelo presidente da Comissão de Constituição e Justiça! [...] Considero que o PDDU 2016 mais uma vez responde a interesses de grupos empresariais do segmento imobiliário, o que pode ser demonstrado através das alterações dos parâmetros de potencial construtivo que possibilitam a elevação do tamanho dos edifícios em toda a cidade, especialmente na Orla Atlântica, a destinação das áreas de Orla Atlântica, Centro Antigo e Península Itapagipana para Operações Urbanas Consorciadas, nas quais setor público e privado se associam para investir. (Entrevista 2 - Vereadora, 2017)

Nessas circunstâncias, o Projeto de Lei elaborado pela prefeitura terminou sendo aprovado com todas as suas disposições e distorções, promovendo uma normatização seletiva dos instrumentos urbanísticos e viabilizando uma utilização que privilegia os interesses de segmentos específicos, sem levar em conta as considerações do debate efetuado pela sociedade e suas proposições. Questões centrais, como maior verticalização da Orla Atlântica e a escala e localização das Operações Urbanas Consorciadas, contestadas pela maioria dos presentes às audiências, continuaram no texto final do Projeto de Lei e do PDDU. ${ }^{8}$

Como assinalam Rebouças e Mourad (2016), mais de $40 \%$ da área de todas as zonas de uso teve elevado o seu gabarito, com um coeficiente de aproveitamento máximo, sem considerar a capacidade de suporte da infraestrutura e de serviços ou a possibilidade de sombreamento das praias e de criação de obstáculos à circulação dos ventos que vêm 
do mar, criando condições para a formação de "ilhas de calor". A utilização de instrumentos como a outorga onerosa ou a Transcon foi sancionada sem a definição de áreas cedentes e áreas receptoras, permitindo sua utilização em todo o território da cidade. A institucionalização de Operações Urbanas Consorciadas para uso em um regime de exceção em grandes áreas do território urbano passou a representar um "cheque em branco" para empresas interessadas. Com a redução das áreas de proteção ambiental e uma flexibilização geral das normas urbanísticas após a aprovação da nova Louos, o próprio secretário municipal de urbanismo, que coordenou com mão de ferro os debates em várias audiências públicas, chegou a afirmar que, "a partir de agora, pode-se tudo em qualquer lugar, tirando as áreas de proteção ambiental tudo é permitido agora" ( $A$ Tarde, 14/8/2016, p. A-4). Questionado sobre o que foi efetivamente incorporado na versão final do Plano como fruto da participação da sociedade, o representante da Fabs afirmou que:

Muito pouco em termos de propostas e de significados. Podemos registrar o aumento do número de Zeis e o registro da chamada cota solidária que orienta os promotores de grandes intervenções urbanas a contribuir com programas de habitação de interesse social. No entanto, apesar da incorporação desses itens que conceitualmente colaboram com maior equanimidade urbana, não ficam claros os critérios e o processo de aplicação dos mesmos, o que pode condená-los a simples "letra morta" na legislação. muito comum na tradição brasileira [...]. De longe, o capital imobiliário pautou e direcionou as principais diretrizes do PDDU. Restringindo áreas de preservação e conservação ambiental e de beneficiamento socioespacial para as camadas mais pobres da cidade. O PDDU obedece a um plano de especulação e crescimento da atuação do capital imobiliário sem levar em consideração os diversos interesses $e$ composição social, racial e de gênero da cidade. (Entrevista 1 - representante da Federação das Associações de Bairros de Salvador - Fabs, 2017)

Significativamente, no que se refere aos interesses das classes populares, o novo PDDU previu apenas a definição de 234 Zeis, um número aparentemente expressivo, mas sem definir um horizonte temporal para os projetos urbanísticos e uma provisão orçamentária para instrumentos e obras. Além disso, a quase totalidade das Zeis previstas está em áreas sem infraestrutura e próximas a outras já ocupadas, em uma lógica de sua ampliação e de uma persistência da segregação e das desigualdades socioeconômicas. No decorrer das entrevistas realizadas, outras declarações nesse sentido também foram obtidas, a exemplo do que afirmou uma outra ativa participante do processo de elaboração do Plano, ressaltando que:

O PDDU não incorporou nada do que foi proposto pelos setores populares ao longo do processo das audiências públicas. Na verdade, é tão pequena a incorporação que, diante do porte do projeto e do ataque que foi perpetrado contra a cidade, o que foi incorporado não foi nada. Podemos registrar a instituição de novas Zeis, por exemplo, a da Gamboa (comunidade tradicional), e a instituição da pedra de Xangó como patrimônio, uma área de proteção cultural. E tudo isso é agravado pelo fato de que, em uma cidade negra como Salvador, a questão racial não é tratada pelo Plano. 
$E$, na queda de braço, na luta entre o capital e os setores populares, quem ganhou foi o capital e quem perdeu foram os trabalhadores. Ainda dessa vez, mais uma vez, o capital ganhou. Nós entregamos aos coordenadores dos trabalhos do plano um saco de cimento e um trator de ouro, pelo modo como esse plano foi construído e pelos benefícios que ele trouxe ao capital. E nós gritamos, nós chamamos a imprensa tentando mostrar o significado do PDDU de 2016 para os cidadãos da cidade de Salvador. (Entrevista 3 - militante do Movimento Sem Teto da Bahia - MSTB, 2017)

\section{Algumas considerações finais}

A recente experiência de elaboração do PDDU de Salvador converte a capital da Bahia em uma metáfora do processo de esvaziamento político da participação e do que alguns autores qualificam como peemedebização da política no Brasil nas últimas décadas. 0 fato é que o recente avanço no processo de democratização da construção do PDDU encontra sérios limites na persistente situação de desigualdade, da qual Salvador se constitui em um exemplo, na radicalização da instrumentalização da participação, com a diluição de projetos políticos tradicionalmente qualificados como distintos, em um contexto de captura do poder público por interesses privados e de esquecimento da política.

0 referido fenômeno da peemedebização da política manifesta-se, nesse caso, na construção de pactos políticos, de uma governabilidade que tem como objetivo, sobretudo, assegurar os interesses das classes que, historicamente, estiveram à frente dos grandes negócios nas nossas cidades. Em uma situação de profunda desigualdade econômica e social, Salvador, à exemplo de outras capitais, institucionaliza um PDDU que não define metas, não estima recursos nem define estratégias, carece de estudos técnicos básicos, descontextualiza a inserção metropolitana de Salvador e sua articulação com o contexto nacional e internacional e não contém diretrizes de desenvolvimento orientadas para reverter o processo de estagnação econômica da cidade. 0 plano não enfrenta adequadamente questões de mobilidade, saneamento, habitação e meio ambiente nem considera a disponibilidade de infraestrutura e de serviços ou os danos ambientais ao possibilitar o adensamento e a verticalização de certas áreas de cidade; possibilita a realização de Operações Urbanas Consorciadas em áreas muito extensas e povoadas de cidade de forma arbitrária, sem garantia de transparência na sua operacionalização e sem uma definição de contrapartidas. Por esses e outros motivos, o PDDU não contribui para a superação da precariedade, da pobreza e das desigualdades nem para assegurar o direito à cidade, conforme diz pretender.

A exemplo do que vem acontecendo em muitas das nossas cidades, o PDDU de 2016 em Salvador se traduz em um retrocesso na configuração político-institucional das estruturas de representação da sociedade civil instituídas ao longo do processo de redemocratização - a exemplo da conversão do Conselho Municipal de Salvador em consultivo. Apesar da vigorosa participação de algumas poucas entidades, de cunho urbanístico, o seu processo de construção se constituiu em um exemplo de desmobilização e instrumentalização de forças e segmentos sociais que, em tese, representariam os interesses coletivos 
e difusos. É isso que explica a reprodução de metodologias de participação convencionais, que não favorecem a participação e a interação - a confusão, deliberada, entre instrumentos como pesquisa de opinião e participação, assim como a falta de representatividade ao longo das audiências públicas.

Apesar da realização das audiências públicas, não existe, de fato, o diálogo - expresso na ausência de retorno por parte do poder público às demandas e na não alteração de conteúdos das propostas apresentadas. É, nesse cenário, que são reforçados os tradicionais comportamentos e as posturas autoritárias, legitimados pela inserção político-institucional e pelo discurso da competência técnica. É esse ambiente, transvestido de democrático, que legitima e protege os antigos e modernos interesses corporativos.
Contudo, não se pode dizer que o processo analisado nada tenha deixado de positivo. Ainda que minoritários, alguns segmentos e organizações conseguiram se mobilizar e se contrapor ao discurso e às orientações oficiais, promovendo um significativo debate sobre as condições e os problemas da capital baiana, apresentando propostas para o seu enfrentamento e, com isso, capacitando-se para novas batalhas da luta pelo direito à cidade. Além disso, conforme assinalado na parte inicial do presente texto, os problemas constatados ao longo da experiência estudada não são exclusivos de Salvador, ainda que tenham aí se acentuado. Na verdade, o que essa experiência mais deixa patente é como a conquista da participação e do direito à cidade, assim como o próprio avanço da democracia no Brasil, ainda têm um difícil e longo caminho a percorrer.

\section{[1] https://orcid.org/0000-0002-0714-9305}

Universidade Católica do Salvador, Programa de Pós-Graduação em Políticas Sociais e Cidadania. Salvador, BA/Brasil.

Universidade Federal da Bahia, Centro de Estudos e Pesquisas em Humanidades. Salvador, BA/Brasil. inaiammc@ufba.br

\section{[II] https://orcid.org/0000-0001-8565-1125}

Universidade Federal da Bahia, Escola de Administração, Núcleo de Pós-Graduação em Administração. Salvador, BA/Brasil.

betesantos@ufba.br 


\section{Notas}

(1) É ilustrativo que levantamentos efetuados pelo Observatório das Metrópoles sobre os programas dos candidatos à prefeitura das cidades de Fortaleza, Recife, Rio de Janeiro, Curitiba e Porto Alegre, nas eleições de 2016, tenham constatado que poucos (filiados a partidos como o PC do B, o PSOL, PSTU ou o PT e normalmente com chances de vitória bastante restritas) se reportaram à participação popular ou aos conselhos, enquanto a grande maioria enfatizava a atração de investimentos, o empreendedorismo e a competitividade urbana. Alguns estudos têm observado que a participação popular e outras práticas inovadoras também têm enfrentado a resistência e/ou a oposição dos vereadores, preocupados com a preservação das práticas clientelistas tradicionais.

(2) Quando esse texto foi escrito, Avritzer não tinha, ainda, se deparado com o fenômeno do impeachment, ou o que parcela significativa da esquerda e do Partido dos Trabalhadores qualificam como "golpe", que interrompe o processo de redemocratização ao qual ele se refere.

(3) O perfil desses participantes mostra um predomínio de representantes de associações de moradores e centros comunitários, estudantes e funcionários públicos.

(4) Declaração da coordenadora oficial do Plano, conforme audiência pública de 11 de junho de 2015. Documento oficial da prefeitura a esse respeito também assinala a intenção de "resgatar o planejamento de longo prazo e orientar o desenvolvimento de Salvador para uma visão do futuro que não seja a mera reprodução das tendências hoje vislumbradas, mas a projeção de um cenário mais promissor, construído com a participação de toda a sociedade, no qual as desigualdades que desde há muito caracterizam a capital baiana sejam gradualmente reduzidas e superadas" (PMS, 2015, p. 1).

(5) Como assinala Santos (2016), o PDDU e a Louos deveriam constituir a quinta etapa do Salvador 500. Na prática, porém, as atividades desse plano e da produção da legislação urbanista em grande parte se confundiram, e a separação entre os projetos tornou-se bastante nebulosa, permitindo que o executivo municipal considerasse como parte do processo de elaboração do PDDU atividades que a priori eram voltadas para o Salvador 500, no caso as oficinas de bairros.

(6) Isso fica patente, por exemplo, em um Informe da Coordenação mencionado por Santos (2016, p. 83), assinalando que, nas oficinas, a população era informada sobre conceitos e desafios do planejamento estratégico, e a Prefeitura ouvia a população sobre as leituras e expectativas a respeito do seu bairro e da cidade. Ao contrário da identificação pretendida pelo Relatório da Oficina dos Bairros, na melhor das hipóteses isso poderia ser qualificado como uma pesquisa de opinião da população sobre o que deveria ser a cidade de Salvador, muito distante do que se poderia considerar como uma participação cidadã nos processos políticos de gestão da res publicas. 
(7) A história do Conselho Municipal de Salvador é repleta de controvérsia. Após sua criação, ele passou muito tempo sem ser convocado. Em fevereiro de 2012, o prefeito João Henrique Barradas Carneiro sancionou a lei n. 8.197, que dispõe sobre o Plano Diretor de Desenvolvimento Urbano do Município de Salvador e em seu art. 297 muda o caráter do Conselho Municipal de Salvador, tornando-o consultivo em matérias relativas ao "planejamento e gestão do uso do solo, habitação, saneamento ambiental e mobilidade urbana, bem como nas demais matérias que afetam o desenvolvimento urbano [...]" (PMS, lei n. 8.197 de 6 de fevereiro de 2012). Segundo o Movimento Participa Salvador, "o Ministério Público (MP-BA) moveu Ação Direta de Inconstitucionalidade (Adin) contra as leis n. 8.167, n. 8.378 e n. 8.379 - todas de 2012 e que alteravam o PDDU (lei n. 7.400/2008) em outros aspectos. A ação foi julgada procedente pelo Tribunal de Justiça da Bahia, e essas leis foram consideradas inconstitucionais". Participa Salvador. Disponível em: http://participasalvador.com.br/2015/03/13/conselho-municipaldeve-ter-cunho-deliberativo. Acesso em: 10 jan 2017.

(8) Ao longo das audiências, vários foram os registros de que, enquanto o Plano estava sendo debatido, a prefeitura já tinha desencadeado, paralelamente, a revisão da Louos, que, em tese, dependeria das suas definições gerais. Vale ressaltar, também, que, não por acaso, as Operações Urbanas Consorciadas - OUCs coincidem com uma Manifestação de Interesse Privado feita pela Odebrecht, envolvendo numerosos e populosos bairros em Salvador.

\section{Referências}

ARANTES, O.; VAINER, C.; MARICATO, E. (2002). A cidade do pensamento único - Desmanchando consensos. Petrópolis, Vozes.

ARANTES, P. E. (2014). O novo tempo do mundo: e outros estudos sobre a era da emergência. São Paulo, Boitempo.

AVRITZER, L. (org.) (2007). A participação social no Nordeste. Belo Horizonte, Editora UFMG. (2010). Experiências nacionais de participação social. Belo Horizonte, Cortez. (2016). Impasses da democracia no Brasil. Rio de Janeiro, Civilização Brasileira.

CARVALHO, I. M. M. de (2013). Capital imobiliário e desenvolvimento urbano. Caderno CRH, v. 26, n. 69, pp. 545-562.

COELHO, L. X. P. (2015). O mito do planejamento urbano democrático: reflexões a partir de Curitiba. Curitiba, Terra de Direitos.

CORIOLANO, G. P.; RODRIGUES, W.; OLIVEIRA, A. F. (2013). Estatuto da cidade e seus instrumentos de combate às desigualdades sócio territoriais: o Plano Diretor Participativo de Palmas. URBE Revista Brasileira de Gestão Urbana, v. 5, n. 2, pp. 131-145.

DAGNINO, E. (org.). (2002). Sociedade Civil e espaços públicos no Brasil. São Paulo, Paz e Terra.

FERNANDES, A. (2008). PDDU 2008: Agonia do Espaço Público. Terra Magazine - Política. Salvador. Disponível em: http://terramagazine.terra.com.br/interna/0,,Ol2705302-El6578,00.html. Acesso em: 28 fev 2016. 
FERNANDES, E. (2010). "O Estatuto da Cidade e a Ordem Jurídico Urbanística”. In: CARVALHO, C. S.; ROSSBACH, A. (orgs.). O Estatuto da Cidade Comentado. São Paulo, Ministério das Cidades.

HARVEY, D. (2005). “Do administrativismo ao empreendedorismo: a transformação da governança urbana no capitalismo tardio". In: HARVEY, D. A produção capitalista do espaço. São Paulo, Anablume.

(2014). Cidades rebeldes. Do direito à cidade à revolução urbana. São Paulo, Martins Fontes.

LEFEBVRE, H. (2001). O direito à cidade. São Paulo, Centauro.

LOGAN, J.; MOLOTOCH, H. (1987). Urban fortunes: the political economy of place. Berkley, Califórnia Press.

MARICATO, E. (2002). Brasil, cidades: alternativas para a crise urbana. Petrópolis, Vozes.

(2010). "O Estatuto da Cidade periférica”. In: CARVALHO, C. S.; ROSSBACH, A. (orgs.). O Estatuto da Cidade comentado. São Paulo, Ministério das Cidades.

MATTOS, C. A. de (2010). Globalización y metamorfosis urbana em America Latina. Quito, Olachi.

MILANI, C. (2007). "Participação social e ação pública local na Bahia”. In: AVRITZER, L. (org.). A participação social no Nordeste. Belo Horizonte, Editora UFMG.

MOTA, A. (2007). "Fissuras na estrutura do mandonismo: transformações recentes e ampliação do escopo democrático na Bahia". In: AVRITZER, L. (org.). A participação social no Nordeste. Belo Horizonte, Editora UFMG.

NASCIMENTO, M. de F. P. (2008). A participação cidadã no Plano de Desenvolvimento Urbano de Salvador. Dissertação de mestrado. Salvador, Universidade Católica do Salvador.

NOBRE, M. (2013). Imobilismo em movimento: da abertura democrática ao governo Dilma. São Paulo, Companhia das Letras.

OBSERVATÓRIO DAS METRÓPOLES (2015). O Direito à Cidade nas Eleições Municipais. Propostas de Governo dos Candidatos à Prefeituras. Rio de Janeiro, setembro de 2016.

PMS (2015). Plano de Mobilização e Participação Social. Salvador. Disponível em: file:///D:/Users/Bete/ Downloads/Plano\%20de\%20Mobiliza\%C3\%A7\%C3\%A3o\%20e\%20Participa\%C3\%A7\%C3\%A3o\%20 Social.pdf. Acesso em: 28 abr 2016.

REBOUÇAS, T.; MOURAD, L. N. (2016). A tampa e a panela ou o casamento das operações urbanas consorciadas com as manifestações de interesse privado na cidade de Salvador - BA. In: SEMINÁRIO URBBA [16]:ESTATUTO DA CIDADE, 15 ANOS: LUTAS, CONQUISTAS E PARADOXOS. Anais... Feira de Santana, Universidade Estadual de Feira de Santana.

SANTOS JUNIOR, O. A.; MONTANDON, D. T. (orgs.) (2011). Os Planos Diretores Municipais Pós-Estatuto da Cidade: balanço crítico e perspectivas. Rio de Janeiro, Letra Capital; Observatório das Metrópole; Ippur/UFRJ.

SANTOS, M. R. M. (2011). “O sistema de gestão e participação democrática nos planos diretores brasileiros". In: SANTOS JUNIOR, O. A.; MONTANDON, D. T. (orgs.). Os Planos Diretores Municipais Pós-Estatuto da Cidade: balanço crítico e perspectivas. Rio de Janeiro, Letra Capital e Observatório das Metrópoles.

SANTOS, R. C. (2016). Quem participa? participação popular e direito à cidade: um estudo de caso do Plano Salvador 500. Dissertação de mestrado. Brasília, Universidade de Brasília. 
SILVA, C. A. (2006). Plano Diretor e Participação Social: pensado o Planejamento Social. Revista Tamoios, ano II, n. 1 (xerox).

VAINER, C. B. (2002). As escalas do poder e o poder das escalas: o que pode o poder local? Cadernos IPPUR/UFRJ, 2001-2/2002-1, pp. 13-32.

VILLAÇA, F. (2005). As ilusões do Plano Diretor. São Paulo, edição do autor.

VITALE, D. (2004). “Democracia direta e poder local: a experiência brasileira do orçamento participativo”. In: COELHO, V. S. P.; NOBRE, M. (orgs.). Participação e deliberação. Teoria democrática e experiências institucionais no Brasil Contemporâneo. São Paulo, Editora 34.

WOLFF, F. (2007). “O esquecimento da política ou o desejo de outras políticas?” In: NOVAES, A. (org.). o esquecimento da política. Rio de Janeiro, Agir.

\section{Avaliações do Plano Diretor}

A TARDE (2016). A nova cara da capital. Lei de Ordenamento do Uso e da Ocupação do Solo e obras de mobilidade mudam perfil de Salvador, p. A4.

CONSELHO DE ARQUITETURA E URBANISMO DA BAHIA - CAU/BA; Instituto de Arquitetos do Brasil. Departamento da Bahia - IAB; Sindicato de Arquitetos e Urbanistas do Estado da Bahia - Sinarq (2016). Nota técnica. Salvador.

NUNES, D.; SERRA, O. (2016). Projeto de Lei do PDDU de Salvador. Uma avaliação. Salvador.

PROJETO PARTICIPA; FÓRUM DA CIDADE É NOSSA; MOVIMENTO VOZES DE SALVADOR. (2016). Os 21 pecados capitais do PDDU de Salvador. (Projeto de Lei 396/2015). Documento elaborado a partir dos debates ocorridos nas Oficinas do Ministério Público e das contribuições do Projeto Participa de especialistas da academia, do Fórum da Cidade é Nossa e do Movimento Vozes de Salvador. Salvador.

\section{Atas do Poder Público Municipal de Salvador}

PMS, Ata da Audiência Pública n. 1, de 2015; PMS, Ata da Audiência Pública n. 2, 2015; PMS, Ata da Audiência Pública n. 3, de 2015; PMS, Ata da Audiência Pública n. 4, de 2015; PMS, Ata da Audiência Pública n. 5, de 2015; PMS, Ata da Audiência Pública n. 6, de 2015; PMS, Ata da Audiência Pública n. 7, de 2015; PMS, Ata da Audiência Pública n. 8, de 2015; PMS, Ata da Audiência Pública n. 9, de 2015; PMS, Ata da Audiência Pública n. 10, de 2015; PMS, Ata da Audiência Pública n. 11, de 2015; PMS, Ata da Audiência Pública n. 12, de 2015; PMS, Ata da Audiência Pública n. 13, de 2015; PMS, Ata da Audiência Pública n. 14, 26 de outubro de 2015; PMS, Ata da Audiência Pública n. 15, de 2015; PMS, Ata da Audiência Pública n. 16, de 2015; PMS, Ata da Audiência Pública n. 17, de 2015; PMS, Ata da Audiência Pública n. 18, de 2015; PMS, Plano de Mobilização e Participação Social - PMPS, Salvador, 2015; PMS, Relatório I - Oficina de Bairros, Salvador, de Janeiro de 2015; PMS, Relatório II - Oficina de Bairros, Salvador, de Janeiro de 2015; Presidência da República, Estatuto da Cidade, lei n. 10.257/2001. Brasília. 


\section{Atas da Câmara de Vereadores de Salvador}

Câmara de Vereadores, Ata da Audiência Pública n. 1, de 2016; Câmara de Vereadores, Ata da Audiência Pública n. 2, de 2016; Câmara de Vereadores, Ata da Audiência Pública n. 3, de 2016; Câmara de Vereadores, Ata da Audiência Pública n. 4, de 2016; Câmara de Vereadores, Ata da Audiência Pública n. 5, de 2016; Câmara de Vereadores, Ata da Audiência Pública n. 6, de 2016; Câmara de Vereadores, Ata da Audiência Pública n. 7, de 2016; Câmara de Vereadores, Ata da Audiência Pública n. 8, de 2016; Câmara de Vereadores, Ata da Audiência Pública n. 9, de 2016; Câmara de Vereadores, Ata da Audiência Pública n. 10, de 2016; Câmara de Vereadores, Ata da Audiência Pública n. 11, de 2016; Câmara de Vereadores, Ata da Audiência Pública n. 12, de 2016; Câmara de Vereadores, Ata da Audiência Pública n. 13, de 2016; Câmara de Vereadores, Ata da Audiência Pública n. 14, de 2016; Câmara de Vereadores, Ata da Audiência Pública n. 15, de 2016; Câmara de Vereadores, Ata da Audiência Pública n. 16, de 2016; Câmara de Vereadores, Ata da Audiência Pública n. 17, de 2016; Câmara de Vereadores, Ata da Audiência Pública n. 18, de 2016; Câmara de Vereadores, Ata da Audiência Pública n. 19, de 2016.

Texto recebido em 29/maio/2017

Texto aprovado em 24/set/2019 